\title{
DESCRIPTION OF A NEW SPECIES OF \\ KROMBEINIUS (HYMENOPTERA: PERILAMPIDAE) \\ FROM THE PHILIPPINES, AND THE PHYLOGENETIC \\ RELATIONSHIPS OF THE GENUS*
}

By D. Christopher Darling

Department of Entomology,

Cornell University, Ithaca, N.Y. 14853

The genus Krombeinius (Hymenoptera: Perilampidae) was recently described (Bouček 1978) to include perilampids with an amalgam of the characters of Euperilampus Latreille and Perilampus Walker. The habitus suggests Euperilampus, and there are two synapomorphies to unite these two genera (Darling 1983): postspiracular sclerite reduced to a narrow triangle, less than one-half as wide as the adjacent pronotum; and pronotum massive, at least one-third the length of the mesoscutum. However, Krombeinius exhibits the wing venation, presence of a marginal rim on the scutellum, and large third metasomal tergite characteristic of Perilampus. I regard these as plesiomorphic similarities. The genus is characterized by the absence of the defining apomorphic characteristics of Euperilampus, i.e., by symplesiomorphy.

In this paper I present new information on the structure of the male genitalia and labrum of the type species of Krombeinius. These structures have proved to be of considerable value in defining genera in the Perilampidae (Darling 1983). From this analysis I suggest autapomorphies for defining Krombeinius. In addition, I describe a new species of Krombeinius from the Philippines, and discuss the affinities of the three included species.

Taxonomic studies of Krombeinius have been hampered by the scarcity of material. The type species, $K$. eumenidarum, was described by Bouček (1978) from a series of specimens ( 2 male, 2 female) reared from the larvae of an eumenine wasp in Sri Lanka. All specimens were prematurely killed and had to be liberated from the pupal cuticles, producing some abnormalities in the type material. Also included by Bouček (1978) in this genus was Perilampus megalaspis Cameron, known only from the type material ( 3 females)

*Manuscript received by' the editor September 22, 1982. 
and an additional female, all from Sarawak, Malaysia. During my study of material in the U.S. National Museum of Natural History, Washington [USNM], I located an additional male specimen of $K$. eumenidarum. This specimen [India: Kerala Survey, 12.5 Pechiparai, 25-27 August 1974] was dissected and re-mounted and is the basis for the description of the labrum and male genitalia. In addition, the C. F. Baker Collection [USNM] contained a new species of Krombeinius from the Philippines, which I describe herein.

Abbreviations used in text: F1-7: funicular segments 1-7; MSC: length of mesoscutum along midline; OOL: length of ocular-ocellar line; PN: length of pronotum along midline; POL: length of posterior ocellar line; SC: length of scutellum along midline; T2-8: metasomal tergites $2-8$.

\section{Krombeinius}

Krombeinius Bouček, 1978: 302, Figs. 1,2.

Type species: Krombeinius eumenidarum Bouček, 1978: 302, Fig. 1. [original designation]

Diagnosis:

Hymenoptera: Chalcidoidea: Perilampidae (sensu Graham, 1969). Species of Krombeinius can be distinguished from Monacon Waterston, Burksilampus Bouček, Steffanolampus Peck and Perilampus Latreille by the narrow postspiracular sclerite, less than one-half the width of the adjacent pronotal panel, and from Euperilampus by having the marginal vein longer than the postmarginal (Fig. 1).

All known species are moderately large, 3 to $51 / 2 \mathrm{~mm}$ long, black without metallic reflections and are restricted to the Oriental region. There are three species currently placed in Krombeinius: K. eumenidarum Boucek, $K$. megalaspis (Cameron) and $K$. saunion, n.sp.

A revised key to the species of Krombeinius is not presented. The key of Bouček (1978) separates K. eumenidarum and K. megalaspis. An additional character to separate these two species is the inner orbits: costate in K. eumenidarum (Fig. 8), and smooth in K. megalaspis (Fig. 12). K. saunion is readily distinguished from these two species by the prominent spine at the apex of the scutellum (Fig. $1,15)$. The apex of the scutellum is truncate in the other two species (Figs. 7,11). 


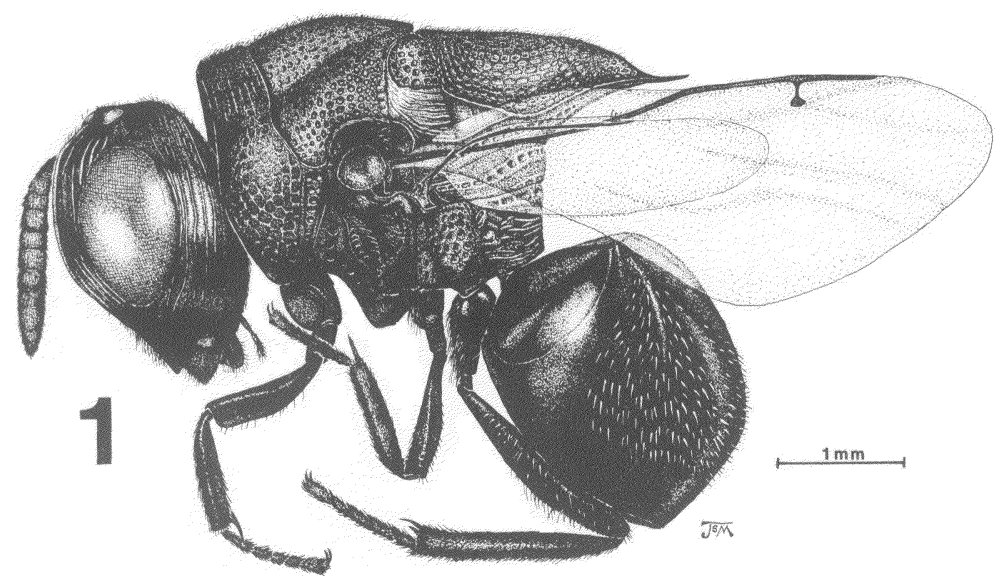

Fig. 1. Krombeinius saunion, lateral habitus.

Description:

Head: supraclypeal area smoothly convex, without horn or ridge; scrobal cavity deep, extending to lower ocular line or to middle of clypeus; clypeus and supraclypeal area separated by distinct suture or by faint line; inner orbits carinate; frontal carina separating the median and posterior ocelli; malar sulcus absent; malar region with strong oblique costae; posterior ocellus located high on vertex, POL approximately equal to OOL; labrum with a single narrow stalk, expanded distally with 7 digits, each with a terminal seta, and with pair of sessile setae not associated with digits, strongly excised medially [ $\mathrm{n}=1, K$. eumenidarum, Fig. 3].

Mesosoma: dorsum of pronotum smoothly convex, without transverse elevations; pronotum massive, about one-third length of mesoscutum, not narrowed medially; mesothoracic spiracle located between pronotum and sidelobe of mesoscutum; postspiracular sclerite fused to the pronotum but delimited by surface sculpture; postspiracular sclerite less than one-half width of adjacent pronotal panel, with many or a single puncture; notauli distinct; scutellum vaulted, jutting over propodeum and base of metasoma; apex of scutellum acuminate, or truncate or with a distinct spine; propodeum with median area foveate, or with a short median ridge, sub- 


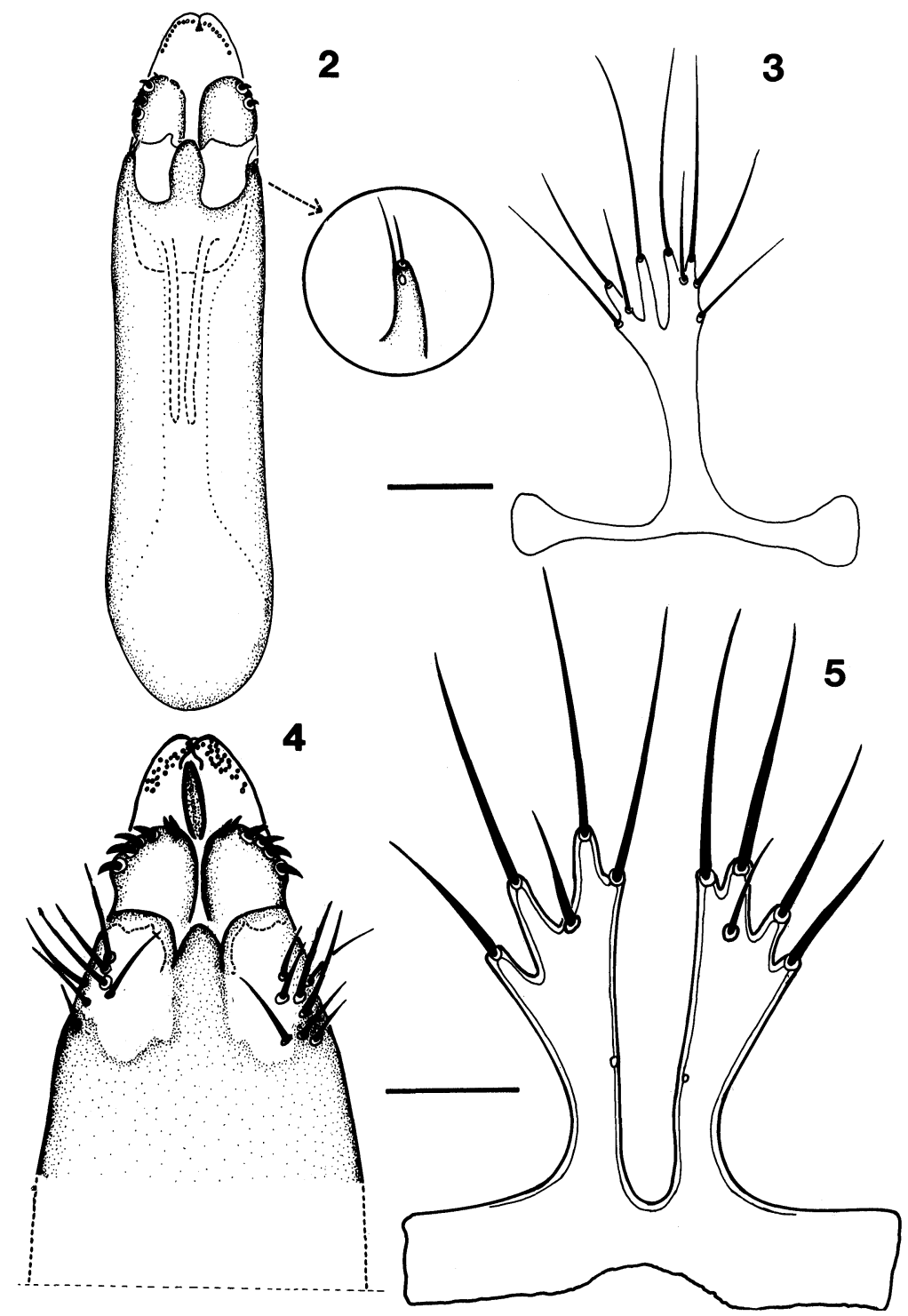

Figs. 2-5. 2,3 Krombeinius eumenidarum. 2. Male genitalia. Inset: enlargement of paramere. 3. Labrum. 4,5. Euperilampus triangularis (Say). 4. Apex of male genitalia. 5. Labrum. [Scale lines $0.1 \mathrm{~mm}$.] 
median areas with weak transverse rugae or aciculate; basitarsomere not conspicuously lengthened. Forewing with marginal vein longer than postmarginal, postmarginal vein long, about 3 times length of stigmal vein, stigmal vein making either a right or oblique angle with marginal vein.

Metasoma: petiole short, transverse, the tergum forming a ridge along anterior face of gaster, sternum shifted posteriorly; gaster triquetrous, T2 and T3 fused, covering most of dorsum; T2 without distinct basal fovea; T3 much longer than T2, subquadrate, slightly wider than length along midline; ovipositor ventral, not upturned, sheaths not distinctly exserted; male genitalia with distinct parameres [ $\mathrm{n}=1$, K. eumenidarum, Fig. 2].

\section{Discussion:}

The male genitalia of Krombeinius eumenidarum (Fig. 2) are similar to those of species of Perilampus: the parameres are distinct, and strong setae are distributed on these lobes. This configuration occurs throughout the Chalcidoidea (see Domenichini 1953) and is regarded as plesiomorphic. In Euperilampus a derived condition is found (Darling 1983): distinct parameres are lacking, and the basiparamere has a patch of strong setae distributed on transparent areas laterad of the ventral lobe (Fig. 4).

The labrum of Krombeinius eumenidarum (Fig. 3) has a narrow central stalk, not found in other perilampid genera (Riek 1966; Domenichini 1969; Darling, unpublished). However, the labrum does share synapomorphies with species of Euperilampus (Fig. 5) including a reduced number of digits ( 7 or 8 ), a pair of smaller, sessile setae not associated with digits, and a strong median excision. The narrow stalk distinguishes the labrum of Krombeinius from those of Euperilampus, and is postulated as an autapomorphy of Krombeinius. All other perilampid labra are 10-12-digitate, and not as strongly excised medially.

The host association of the type species of Krombeinius [larva of Vespidae: Eumeninae] is different from that of any other described perilampid, although solitary Sphecidae are attacked by some Perilampus species (e.g., Perilampus nitidus, primary parasitoid of Ectemnius paucimaculatus. Krombein 1964, as P. (canadensis). This behavioral character is regarded as an additional autapomorphy for the genus Krombeinius. 

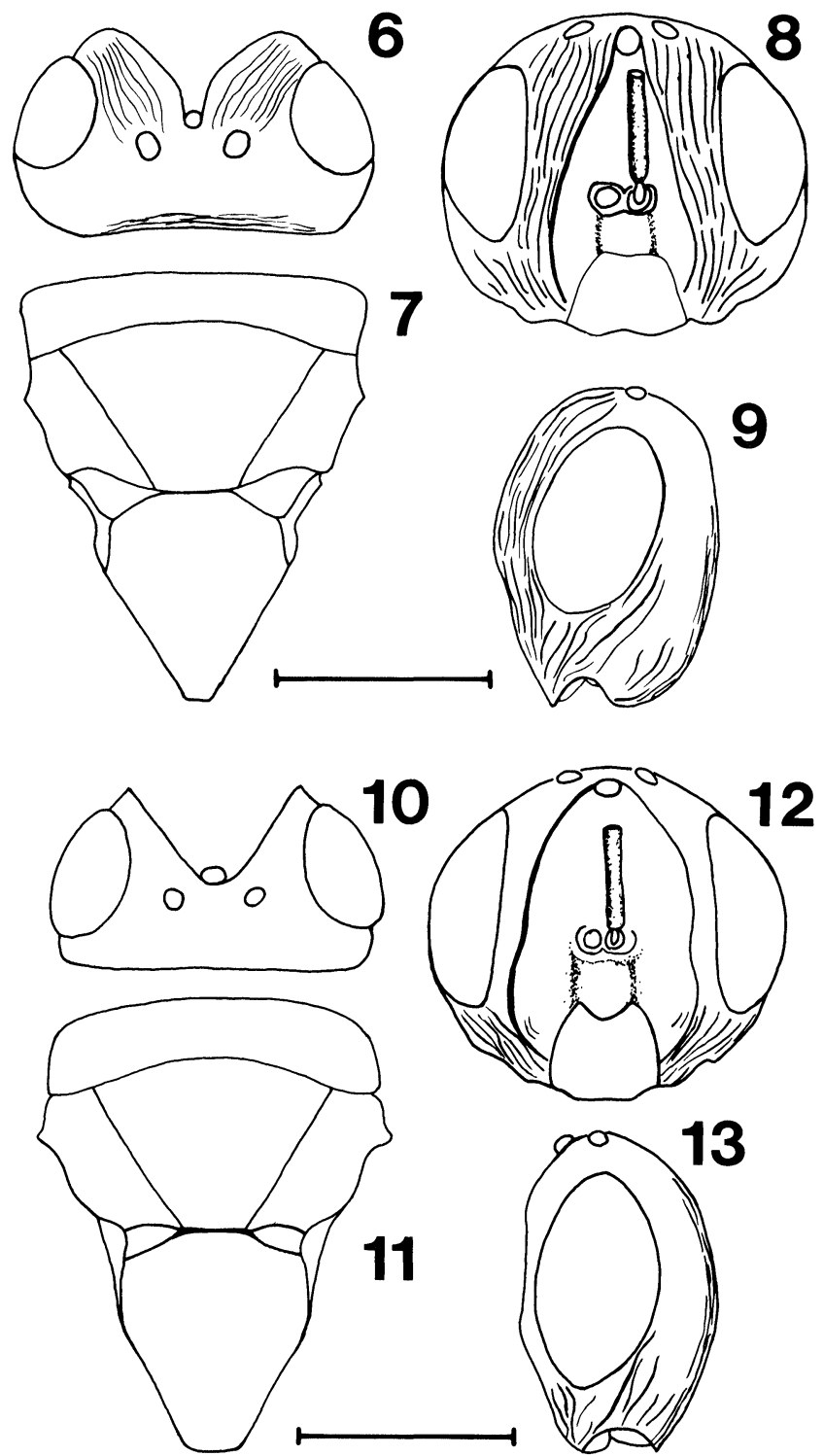

Figs. 6 13. 6 9. Krombeinius eumenidarum. 6. Head, dorsal. 7. Mesosoma, dorsal. 8. Head, frontal. 9. Head, lateral. 10-13. K. megalaspis. 10. Head, dorsal. 11. Mesosoma, dorsal. 12. Head, frontal. 13. Head, lateral. [Scale line $1 \mathrm{~mm}$.] 


\section{Krombeinius sauion n.sp.}

(Figs. 1, 14-17)

Type Locality: Philippines, Mindanoa, Surigao.

Type Material: Holotype: Female [Baker Collection, USNM].

Etymology: The specific epithet is a noun in apposition, Greek for "javelin", and is a reference to the elongate spine on the scutellum of this species.

\section{Diagnosis:}

This species can be immediately recognized by the prominent spine at the apex of the scutellum (Figs. 1, 15). The apex of the scutellum is truncate in $K$. eumenidarum (Fig. 7) and $K$. megalaspis (Fig. 11).

\section{Description:}

Female: Length, $5.4 \mathrm{~mm}$. Black, except tegula and flagellum brown, mandible reddish-brown, apex of foretibia and spur, and tarsi yellow; wings hyaline, veins darkened.

Head: length of malar space 0.34 eye height; OOL 0.95 POL; maximum width of scrobe 0.56 head width; head transverse, width: height $=1.17$; inner and outer orbits costate, costae convergent on clypeus; scrobal cavity deep and wide, extending below lower ocular line and delimiting clypeus and supraclypeal area; clypeus transverse, width:height $=1.31$, polished and covered with long setae; clypeus not delimited by sutures, upper margin indicated by a faint line, tentorial pits distinct, lower margin weakly emarginate; ocularocellar region with costae radiating from posterior ocellus; vertex with strong costae at posterior margin; supraclypeal area glabrous, height 0.51 clypeus height; lateral wall of scrobe merging smoothly with face; lower tooth of mandible pointed at apex; base of mandible with weak punctures; labio-maxillary complex short. Antenna: scape narrowly linear, length 8.5 maximum width; pedicel and funicular segments subequal in length (18 versus $14,15,17,16,15$, $15,13 ; \mathrm{F} 1-\mathrm{F} 7)$; pedicel 0.21 scape length; anellus 0.43 length of $\mathrm{F} 1$; F1 elongate, remaining flagellomeres transverse; clava 0.25 length of funicle.

Mesosoma: pronotum massive, $\mathrm{PN}: \mathrm{MSC}=0.34$, lateral pronotal collar not regularly convex, suggesting bumpy shoulders; scutellum acuminate with a long spine, $\mathrm{SC}: \mathrm{MSC}=1.75$; dorsum of pronotum 
punctate-reticulate, punctures coalesced to form weak irregular transverse costulae medially; midlobe of mesoscutum and scutellum weakly punctate, becoming punctate-reticulate along notauli; sidelobe of mesoscutum smooth along notauli, laterally punctatereticulate; notauli distinct; scutellum in lateral view tapering abruptly towards apex (Fig. 1; cf. Figs. 1,2 in Bouček 1978); underside of scutellum mostly coriarious, with shallow convergent grooves; propodeum vertical, medially about twice as long as metanotum, with weak median ridge, submedian areas with transverse costulae, callus reticulate-rugose; width of postspiracular sclerite 0.44 width of adjacent pronotal collar, with about 10 foveae; axilla reticulate above, costate below; axillula smooth.. Forewing: submarginal:marginal:postmarginal:stigmal veins as $64: 17: 12: 4$; stigmal vein making a right angle ( 90 degrees) with marginal vein.

Metasoma: T2 smoothly concave with weak coriarious sculpture; $\mathrm{T} 2$ with sparse setae, without punctures, border between $\mathrm{T} 2$ and $\mathrm{T} 3$ indicated by a suture, laterotergite glabrous; T3 massive and convex, about twice length of $\mathrm{T} 2$ along midline, length about equal to maximum width ( 22 versus 25 ), evenly covered with long setae except along T2 border and along margins of tergite, without punctures.

Male: Unknown.

\section{Discussion:}

Krombeinius saunion is more closely related to K. eumenidarum than to K. megalaspis. Synapomorphies of these two species are: the stigmal vein making a right angle with the marginal vein (oblique in K. megalaspis and outgroup: Euperilampus and Perilampus); clypeal-supraclypeal margin weak or indistinct (separated by distinct suture in K. megalaspis and outgroup: Euperilampus and Perilampus); lateral pronotal collar suggesting bumpy shoulders (regularly convex in K. megalaspis and outgroup: Euperilampus and Perilampus); and postspiracular sclerite with many foveae (a single fovea is found in K. megalaspis, and in the ancestral species groups of Euperilampus, Darling 1983). Considering Euperilampus as the outgroup, the following similarities of $K$. eumenidarum and $K$. saunion are regarded as plesiomorphic: propodeum medially about twice as long as metanotum (equal to metanotum in K. megalaspis; autapomorphy); scutellum, in lateral view, not strongly convex, tapering gradually towards the apex (highly convex in $K$. megalaspis, Bouček 1978: Fig. 2; autapomorphy). 
$K$. saunion and $K$. eumenidarum also have the inner orbits with strong costae (Figs. 8,9,16,17), whereas the inner orbits of $K$. megalaspis are smooth (Figs. 12,13). I consider the costate inner orbits to be a synapomorphy of Euperilampus + Krombeinius. As such I interpret the smooth orbits of $K$. megalaspis as an autapomorphic reversal. A similar reversal in this character is indicated in the Euperilampus cladogram (Darling 1983).

There remain some difficulties in justifying the current composition of the genus Krombeinius. The numerous characters separating

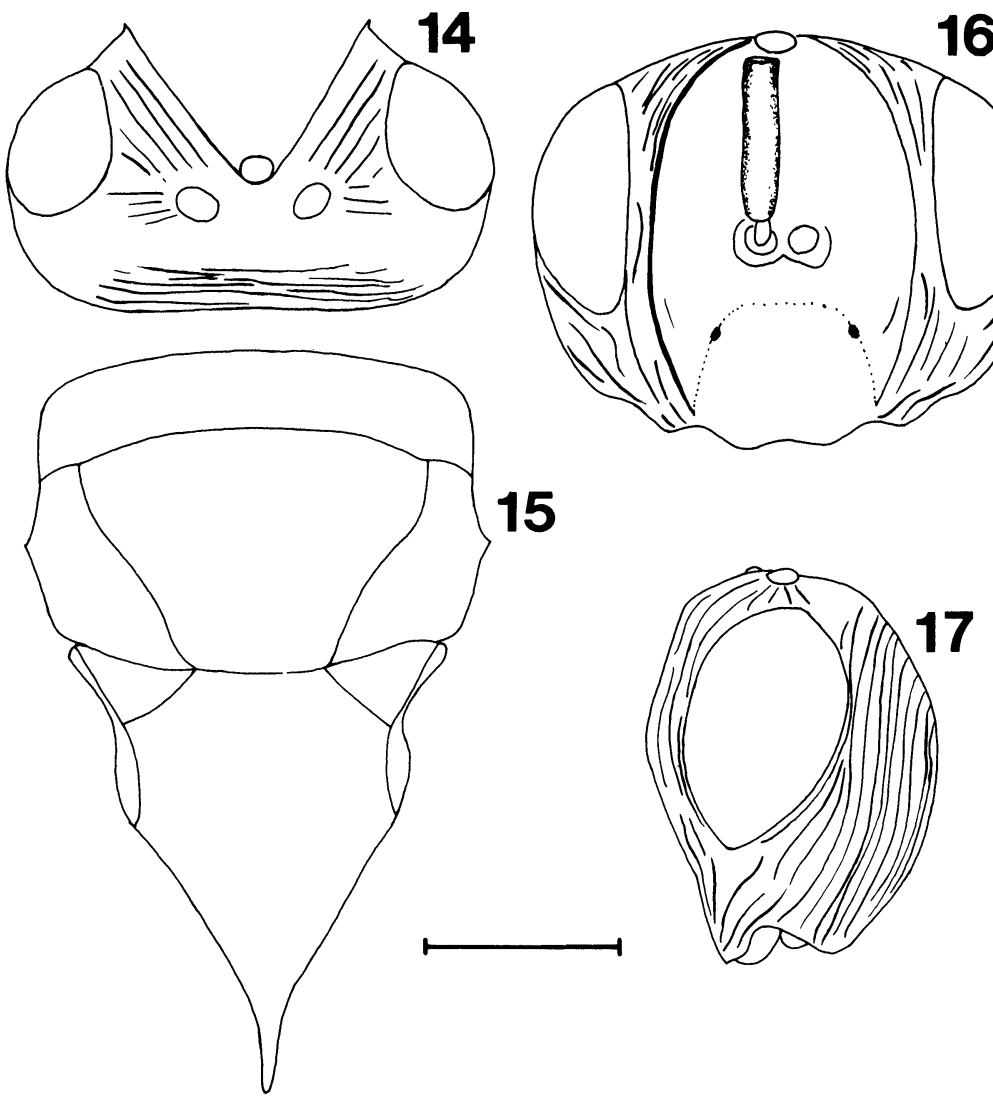

Figs. 14-17. Krombeinius saunion. 14. Head, dorsal. 15. Mesosoma, dorsal. 16. Head, frontal. 17. Head, lateral. [Scale line $1 \mathrm{~mm}$.] 
$K$. eumenidarum $+K$. saunion from $K$. megalaspis question the inclusion of $K$. megalaspis. A revised classification would create a monobasic new genus for Perilampus megalaspis, and would allow Krombeinius to be defined by the synapomorphies of $K$. eumenidarum + K. saunion. Recalling that the proposed synapomorphies of Krombeinius (structure of the labrum; host association) are not known for K. megalaspis, it would not be surprising if this species were to be excluded at some later date. Clearly, more material and associated biological information are essential to re-evaluate the composition of Krombeinius, and any nomenclatural changes at this time would be premature.

\section{ACKNOWLEDGMENTS}

I would like to thank the following people for comments on the manuscript: W. L. Brown, Jr., J. M. Carpenter, G. C. Eickwort, S. W. Nichols, and Q. D. Wheeler.

The habitus drawing was skillfully prepared by Jim Miller.

This research was supported in part by a National Science Foundation Dissertation Improvement Grant.

\section{Literatire: Cited}

Bos ¿̌́k, Z. 1978. A generic key to Perilampinae (Hymenoptera, Chalcidoidea), with a revision of Krombeinius n. gen. and Euperilampus Walker. Entomologica scandinavica 9:299 307.

DARIING, D. C. 1983. A review of the New World species of Euperilampus (Hymenoptera: Perilampidae), with notes about host associations and phylogenetic relationships. In press, Quaestiones entomologicae.

Dominichini, G. 1953. Studio sulla morphologia dell'addome delgi Hymenoptera Chalcidoidea. Bollettino di Zoologia Agraria e Bachicoltura, 19:183-298, 27 ligs.

Domenichini, G. 1969. Materiali per la morfologia comparata degli Hymenoptera Chalcidoidea. Memorie della Societa Entomologica Italiana, 48:584-608, 53 figs.

Granam, M. W. R. DE V. 1969. The Pteromalidae of north-western Europe (Hymenoptera: Chalcidoidea). Bulletin of the British Museum (Natural History) Entomology Supplement 16.908 pp.

KrombeIN, K. V. 1964. Natural History of Plummers Island, Maryland XVIII. The hibiscus wasp, an abundant rarity, and its associates (Hymenoptera: Sphecidae). Proceedings of the Biological Society of Washington, 77:73-112.

Rit:, E. F. 1966. Australian Hymenoptera Chalcidoidea, Family Pteromalidae, Subfamily Perilampinac. The Australian Journal of Zoology, 14:1207-1236. 

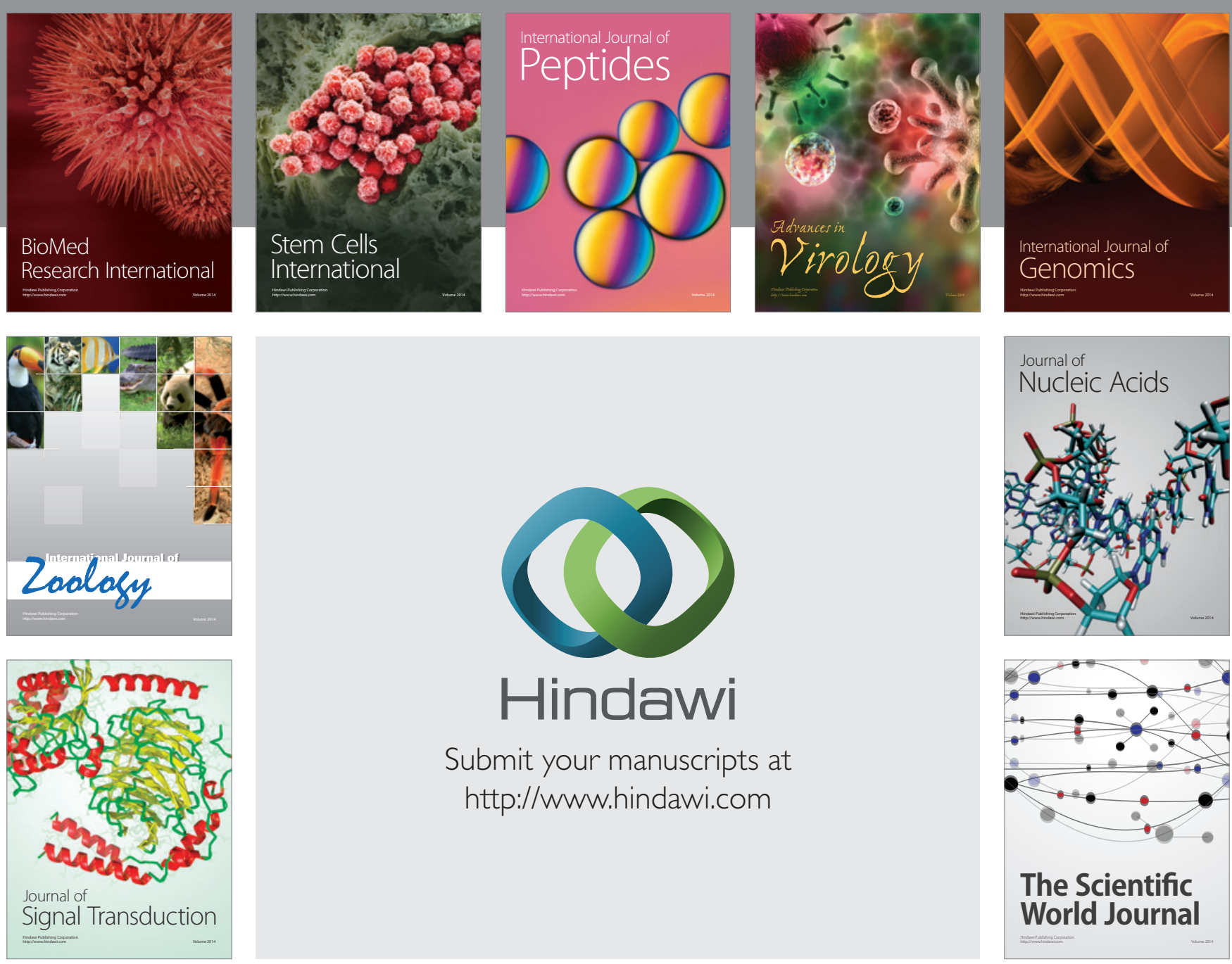

Submit your manuscripts at

http://www.hindawi.com
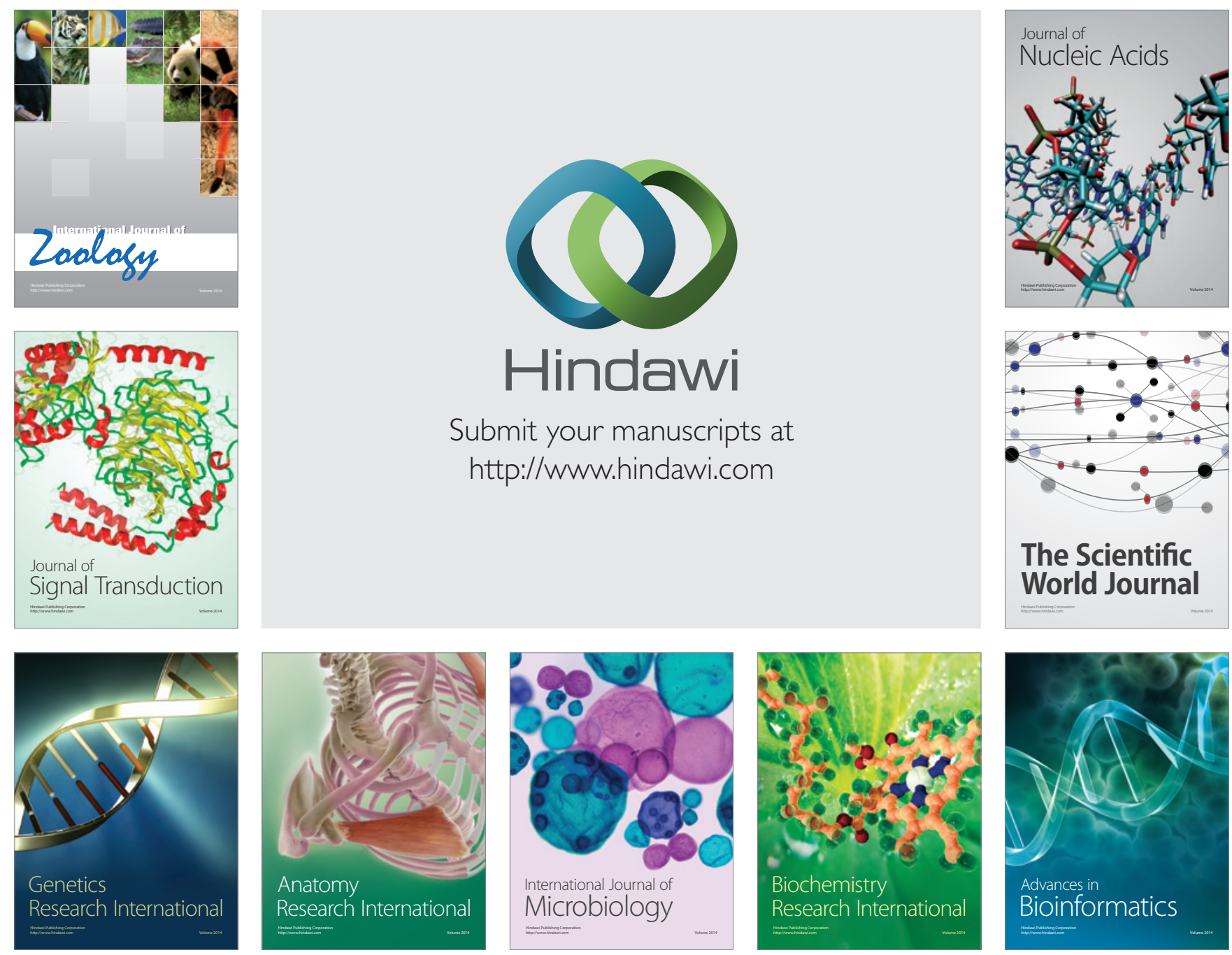

The Scientific World Journal
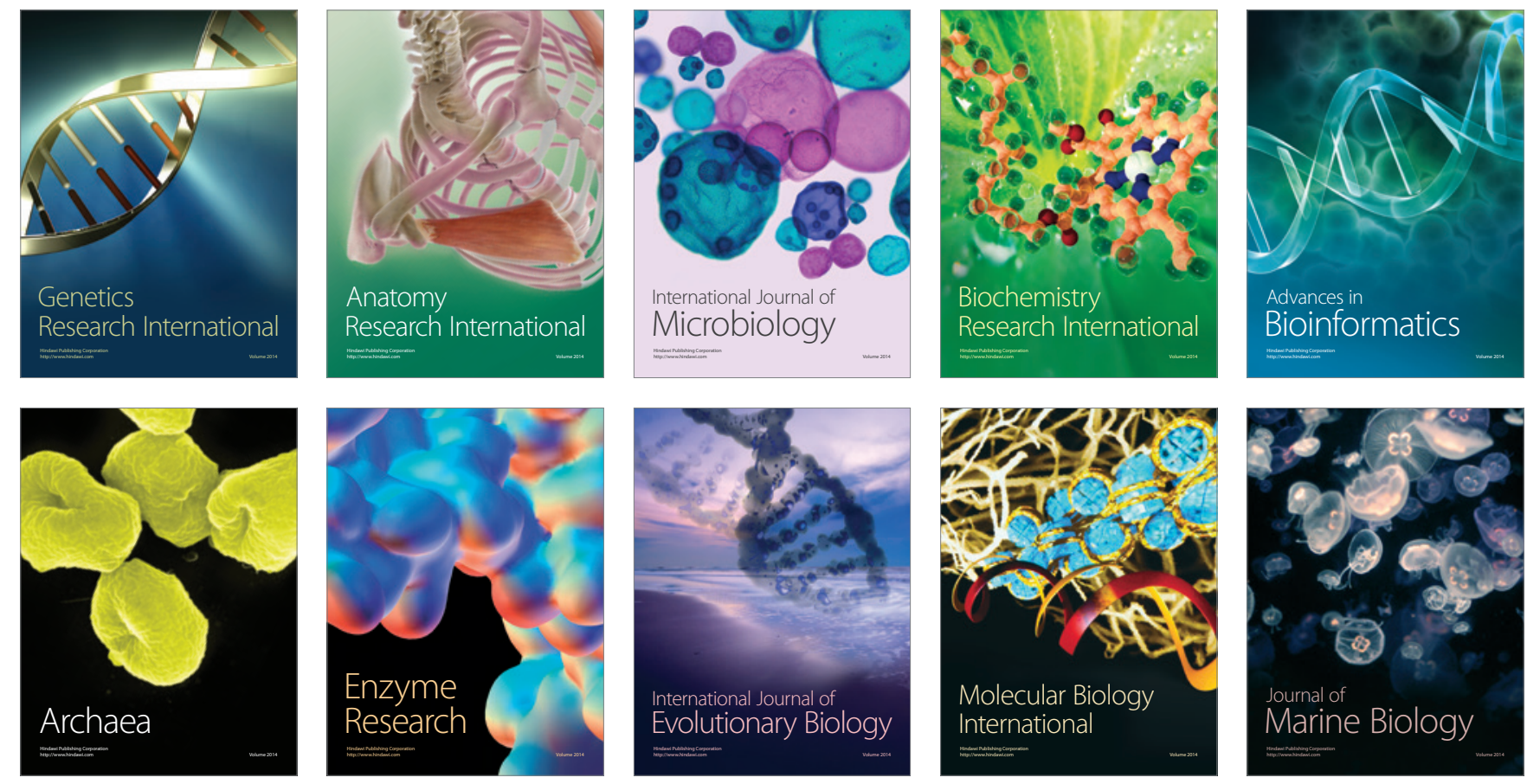